\title{
LA IMPUTACIÓN SEGÚN Kant. ¿RECONOCE ESTE AUTOR DIVERSOS NIVELES DE ANÁLISIS?
}

[Imputation in Kant's work. Does this Author Recognize Different Levels of Analysis?]

\author{
Dr. iUr. Nicolás Santiago Cordini, LL.M.*
}

\section{RESUMEN}

Cotidianamente imputamos acciones. Todas las valoraciones de nuestro accionar transitan por los polos de la alabanza y el reproche. Toda imputación requiere como objeto la conducta de una persona. El núcleo del concepto en cuestión se encuentra en la acción y efecto de atribuir un determinado fenómeno a un sujeto como su obra. El interés por abordar una teoría que podríamos calificar de "olvidada" viene dado por el renacimiento de los estudios sobre la imputación, tanto desde la filosofía práctica como desde el Derecho penal. En el presente trabajo queremos detenernos en el

\section{ABSTRACT}

Daily, we impute actions. All the assessments of our actions transit between the poles of the praise and the reproach. All imputation requires as object an action of a person. The core of the concept in question lies in the action and the effect of ascribing a certain event as a deed of a person. The interest to address a theory, that we could qualify as "forgotten", is given by the revival of the studies about the imputation, as many from the Practice Philosophy as from the Criminal Law. In this paper, we would like to analyse the theory of imputation developed by Kant. Although this author doesn't analytically identify the different

RECIBIDO el 31 de octubre y APROBADO el 30 de diciembre de 2016

* Becario Postdoctoral del CONICET en el Instituto Ambrosio L. Gioja Facultad de Derecho - Universidad de Buenos Aires; Profesor de Derecho penal I, Facultad de Ciencias Jurídicas y Sociales - Universidad Nacional del Litoral, Av. Coronel Díaz 2437, 6 E, Ciudad Autónoma de Buenos Aires, CP: 1425, Argentina, ncordini@fcjs.unl.edu.ar. 
estudio de la teoría de la imputación desarrollada por Kant. Si bien este autor, al definir a la imputación, no distingue analíticamente entre los diversos niveles que la componen, para una mejor comprensión del sistema de imputación, lo analizaremos a partir de las categorías según las cuales era analizada esta teoría en el siglo xviii, a saber: imputatio facti, applicatio legis ad factum e imputatio iuris.

\section{Palabras Clave}

Kant -imputación - consecuencias. levels that make it up, in order to get a better understanding of the system of imputation, we will analyse it from the categories under which it was analysed in the xviii century, namely: imputatio facti, application legis ad factum and imputatio iuris.

KEYWORDS

Kant - imputation - consequences.

\section{INTRODUCCIÓN**}

Cotidianamente juzgamos nuestra conducta y la de terceros; cuando las observamos, no la describimos en términos causales sino que, ante un determinado suceso -sea un movimiento corporal o un sonido-, le imputamos una determinada acción, o sea, lo 'comprendemos'. Así, por ejemplo, para describir la conducta de un monje no recurrimos a la explicación causal. Sus movimientos consistentes en arrodillarse y permanecer inmóvil los comprendemos en el contexto de la vida monacal. Pero, ¿por qué imputamos al monje arrodillado e inmóvil la acción de orar? Se debe a que las prácticas humanas están amparadas en expectativas normativas; encarnan ideas sobre qué es aquello a lo que uno tiene derecho a esperar del otro. ${ }^{1}$ Comprender las acciones de otros presupone que somos sujetos

** En adelante se utilizarán las siguientes abreviaturas para las obras de Kant, teniendo en cuenta su título en alemán, así: KaNT, Immanuel, Vorlesung zur Moralphilosophie $(=V M P)$, en STARK, Werner (editor) (Berlin, Walter de Gruyter, 2004); Moralphilosophie Collins (=MPC), en AKADEMIE DER WisSENSCHAFTEN DER DDR (editor), Kant's gesammelte Schriften (Berlin, Walter de Gruyter, 1974), XXVII/1.1, pp. 237-473; Praktische Philosophie Powalski (=PPP), en AKAdEMIE Der WissensCHAFTEN DER DDR (editor), Kant's gesammelte Schriften (Berlin, Walter, 1974), XXVII/4-1, pp. 91-235; Metaphysik der Sitten Vigilantius (=MdS-V), en AKADEMIE DER WISSENSCHAFTEN DER DDR (editor), Kant's gesammelte Schriften (Berlin, Walter de Gruyter, 1974), XXVII/4-2, pp. 479-732; Lose Blätter zu den Fortschritten der Metaphysik (=LBFM), en Preussischen AKademie der Wissenchaften (editor), Kant's gesammelte Schriften (Berlin-Leipzig, Walter de Gruyter, 1942), XX, pp. 333-351; Erläuterungen zu A. G. Baumgartens. Initia Philosophiae practicae Primae (=EB), en Preussischen AKademie der Wissenchaften (editor), Kant's gesammelte Schriften, Berlin-Leipzig, Walter de Gruyter, 1934), XIX, pp. 5-89; Reflexionen zur Moralphilosophie $(=R M P)$, en Preussischen Akademie der Wissenchaften (editor), Kant's 
seguidores de normas. Las instituciones encarnan ideas y, al mismo tiempo, están constituidas por las relaciones sociales y sus reglas. ${ }^{2}$ Las "formas de vida"3 involucran un comportamiento guiado, gobernado por reglas. ${ }^{4} \mathrm{El}$ comportamiento "regido por reglas" es esencialmente social. ${ }^{5} \mathrm{El}$ mismo supone convenciones y acuerdos intersubjetivos dado que, los sujetos

gesammelte Schriften, (Berlin-Leipzig, Walter de Gruyter, 1934), XIX, pp. 92-317; (1797) Die Metaphysik der Sitten $(=M d S)$, en Königlich Preussischen Akademie DER WiSSENCHAFTEN (editor), Kant's gesammelte Schriften, (Berlin, Walter de Gruyter, 1907), VI, pp. 203-492. Para la Teoría del derecho (Rechtslehre) se utilizará (MdS-R) y para la Teoría de la virtud (Tugendlehre) (MdS-T) respectivamente; (1795) Zum ewigen Frieden. Ein philosophischer Entwurf $(=Z e F)$, en KöNiglich PreußischeN AKademie der Wissenchaften (editor), Kant's gesammelte Schriften (Berlin-Leipzig, Walter de Gruyter, 1921), VIII, pp. 341-386; (1785) Grundlegung zur Metaphysik der Sitten $(=G M d S)$, en Königlich Preussischen Akademie der Wissenchaften (editor), Kant's gesammelte Schriften, Berlin, Walter de Gruyter, 1903), IV, pp. 385446; (1781) Kritik der reinen Vernunft (=KrV) (Stuttgart, Reclam, 2013).

${ }^{1}$ Hollis, Martin, Filosofía de las Ciencias Sociales (traducción castellana de Ana Lizón, Barcelona, Ariel, 1998), p. 160.

${ }^{2}$ Para comprender la conducta de los monjes es necesario tener en cuenta la vida cotidiana del monasterio como expresión de las reglas que otorgan significado a sus conductas. Así, los tres nudos en el extremo del cordón que llevan algunos monjes significan los votos de pobreza, castidad y obediencia. Los votos otorgan sentido a los nudos, y las ideas de una realidad espiritual encanada en la orden monástica otorgan sentido a los votos. Hollis, Martin, cit. (n. 1), p. 172.

${ }^{3}$ Wittgenstein define al lenguaje, entre sus múltiples acepciones, como una "forma de vida"; al respecto sostiene: "imaginar un lenguaje significa imaginar una forma de vida” (19); “¿Dices, pues, que la concordancia de los hombres decide lo que es verdadero y lo que es falso?' - Verdadero y falso es lo que los hombres dicen; y los hombres concuerdan en el lenguaje. Ésta no es una concordancia de opiniones, sino una forma de vida" WitTGENSTEIn, Ludwig, (1953), Investigaciones filosóficas (traducción castellana de Alfonso García Suárez y Ulises Moulines, Barcelona, Atalaya, 1999, p. 13; p. 78.

${ }^{4}$ Winch sostiene que el comportamiento regido por reglas es esencialmente social. El mismo supone convenciones y acuerdos intersubjetivos. Los sujetos, cuando actúan, lo hacen mediante la aceptación y la observancia de reglas, aunque las mismas permanezcan implícitas. Al respecto aclara: "El concepto de seguir una regla (...) Sugiere que se han de tener en cuenta no sólo las acciones de la persona cuya conducta como candidato para la categoría de seguidor de reglas está en cuestión, sino también las reacciones de otros individuos ante lo que él hace. Dicho de manera más específica solo en una situación en la que tiene sentido suponer que alguien más puede, en principio, descubrir la regla que estoy siguiendo, es posible decir inteligiblemente que estoy, de algún modo, siguiendo una regla" W $\mathrm{INCH}_{\mathrm{N}}$ Peter (1958) The Idea of a Social Science and its Relation to Philosophy (London, Routledge, 2003), p. 30. Todas las traducciones del inglés, del alemán y del francés al español son de nuestra autoría, salvo que se indique lo contrario.

5 Bernstein, Richard, La reestructuración de la teoría social y política (traducción 
cuando actúan, lo hacen mediante la aceptación y la observancia de reglas, aunque las mismas permanezcan implícitas.

Toda imputación requiere como objeto la conducta de una persona. El núcleo del concepto en cuestión se encuentra en la acción y en el efecto de atribuir un determinado fenómeno a un sujeto como su obra (bajo su responsabilidad), lo que supone de antemano una acción confrontada a una prescripción o a una prohibición. Este movimiento que se dirige de la imputación hacia la responsabilidad del sujeto no debe perder de vista el juicio inverso, que va desde la retribución del hecho a la acción del autor y conlleva, ${ }^{6}$ a su vez, la pregunta en el ámbito jurídico, de quién es el sujeto susceptible de imputación o, en otros términos, quién es persona para el Derecho.

La imputación se remonta hasta los inicios de la civilización. El principio de imputación, o sea, la atribución de sentido, era el modo que utilizaban las sociedades primitivas para comprender el mundo. No sólo recurrían a este modo de comprensión para explicar sus relaciones sociales, sino que el modo en que concebían dichas relaciones servía para explicar los fenómenos naturales y sólo muy tardíamente en el devenir histórico, ${ }^{7}$ la explicación causal suplantó a la interpretación socionormativa de la naturaleza. El primer análisis filosófico de la imputación se encuentra en la Ética nicomaquea de Aristóteles, concepto que siguió siendo estudiado tanto desde la filosofía aristotélico-tomista, como desde el racionalismo con autores como Samuel Pufendorf y Christian Wolff, pasando por el idealismo alemán con Immanuel Kant y Georg Wilhelm Friedrich Hegel.

Las teorías de la imputación (Zurechnungslehren) eran el modo de comprensión utilizado para determinar cuándo una conducta constituía una acción meritoria, una acción debida o bien, una acción demeritoria. Estas teorías fueron abandonadas en el campo jurídico a partir del establecimiento de la dogmática jurídico-penal como disciplina científica y con ella, la teoría del delito (Verbrechenslehre) como el modo de comprender el hecho punible. El interés por abordar una teoría que podríamos calificar de "olvidada" viene dado por el renacimiento de los estudios sobre la imputación, tanto desde la filosofía práctica como desde el Derecho penal. En el presente trabajo queremos detenernos en el estudio de la teoría de la imputación desarrollada por Kant. Para ello nos detendremos, fundamentalmente, en el análisis de la imputación, que hace el filósofo en cuestión,

castellana de Eduardo L. Suárez, Ciudad de México, Fondo de Cultura Económica, 1982), p. 94.

${ }^{6}$ Riceeur, Paul, "Le concept de responsabilité. Essai d'analyse sémantique”, EL MISMO, Le juste I (Paris, Esprit, 1995), p. 45.

${ }^{7}$ Kelsen, Hans, Reine Rechtslehre (Wien, Franz Deuticke, 1960), p. 86. 
en la La metafísica de las costumbres (MdS), aunque también serán de gran aporte otros conceptos estrechamente vinculados al anterior, presentes en sus obras. Por último, también serán de gran utilidad el desarrollo que Kant ha hecho de esta teoría en sus clases, que llegan a nosotros a partir de la obra no publicada por el propio Kant, especialmente las hojas sueltas y las Lecciones sobre filosofía moral. ${ }^{8}$ Hasta la actualidad existen pocos estudios sistemáticos sobre el concepto "imputación” en la filosofía práctica de Kant. Una razón puede ser que las declaraciones explicitas que Kant realiza acerca la imputación se limitan a pocos pasajes en la Introducción a la MdS. Esto no es sólo sorprendente en consideración de la relevancia del concepto "imputación” sino también en consideración del hecho de que el propio Kant erigió en un lugar central de su filosofía práctica al concepto en cuestión, ${ }^{9}$ como lo demuestra una observación en las hojas sueltas de los avances de la metafísica de las costumbres. („Lose Blätter zu den Fortschritten der Metaphysik"). En dicha hoja Kant expresa que "el origen de la filosofía práctica es la moral, en consideración de la capacidad de imputación de las acciones". ${ }^{10}$

${ }^{8}$ El legado manuscrito (handschrifticher Nachlass) se clasifica de la siguiente manera: por un lado se incluyen los "manuscritos", es decir, los bocetos de obras publicadas por el autor. Estos bocetos fueron publicados de manera independiente en Akademie Ausgabe, tomo XXIII. En él se recogen diversos manuscritos que se refieren a obras publicadas o cuya publicación estuvo planificada por el propio Kant. LEHMANN, Gerhard, "Vorwort", KANT, Immanuel, Kant's gesammelte Schriften (Berlin, Walter de Gruyter,1955), XXIII, p. V. Luego están los "apuntes” o "glosas" hechas sobre los ejemplares que Kant tenía de otros textos, ya sea propios o ajenos. Por último, los manuscritos conocidos como "hojas sueltas" (löse Blätter). Fue Reicke quien definió, correctamente, como hojas sueltas a esta especie de manuscritos que conforman el legado de Kant. Pues, sólo raras veces existe entre ellas una conexión exterior reconocible, aún más raro es que ellas estén en una situación ordenada, a través de una numeración, en una gran relación. Éstas últimas, están compuestas por un conjunto de papeles, sobre diversas temáticas de las cuales resulta prácticamente imposible ordenarlas y darles una coherencia lógica. Adickes nos reseña que "era costumbre de Kant, anotar en tales papeles, asuntos científicos que a él le interesaban, lo ocupaban, lo atormentaban o simplemente, aquello que se le pasaba por la cabeza y que sin una ayuda como ésta fácilmente se le podían escapar". ADICKES, Erich, (1911) "Einleitung in die Abtheilung des handschriftlichen Nachlasses", en KaNT, Immanuel, Kant's gesammelte Schriften (Berlin-Leipzig, Walter de Gruyter, 1925), XIV, p. XVIII.

9 BlÖSER, Claudia, Zurechnung bei Kant. Zum Zusammenhang von Person und Handlung in Kants praktischer Philosophie (Berlin, Walter de Gruyter, 2014), p. 6.

10 "Ursprung der critischen [sic] Philosophie ist Moral, in Ansehung der Zurechnungsfähigkeit der Handlungen” KANT, Immanuel, "Lose Blätter zu den Fortschritten der Metaphysik, en Preussischen Akademie der Wissenchaften (editor), Kant's gesammelte Schriften, Berlin-Leipzig, Walter de Gruyter, 1942), XX, p. 335. 


\section{LA IMPUTACIÓN SEGÚN KANT}

La imputación presentada por Kant en la MdS no es una teoría que él elabora desde cero, sino que tomó los aportes de otros filósofos que ya habían trabajado esta teoría, entre ellos Wolff o Baumgarten, para desarrollar su propio sistema. Lo interesante del modelo kantiano es el cambio de perspectiva, la teoría de la imputación no es abordada desde la óptica del sujeto agente, sino desde el sujeto imputante. El abordaje de esta doctrina se encuentra en la Introducción a la $M d S$, siendo el mismo válido para ambas teorías desarrolladas dentro de esta obra a saber, la $M d S-R$ y $M d S-T$. En otras obras, no publicadas por él, como por ejemplo en las Lecciones sobre filosofía moral, y en particular, en la MdS-V ${ }^{11}$ o bien, en $\mathrm{RMP}^{12}$ () (Reflexiones sobre filosofía moral) encontramos aportes que permiten complementar el desarrollo hecho en la MdS.

En la Introducción de la MdS, Kant señala que la "Imputación

11 Johann Friedrich Vigilantius (1757-1823) fue un abogado y funcionario de Königsberg amigo personal de Kant que tomó notas del curso sobre Metafísica de las Costumbres de Kant. Vigilantius tenía 36 años y era ya un experto jurista cuando auditó el curso en 1793-1794. Las notas de Vigilantius no están exentas de problemas, el texto en alemán es solamente una copia del texto original de Vigilantius, que se ha perdido. No existe seguridad en quien produjo la copia. La misma fue preparada por varias personas, todavía de identidad indeterminada, pero presumiblemente asociadas con Rudolph Reicke o Emil Arnoldt y preparadas en el inicio del 1800 bajo la denominación "Metaphysik der Sitten Vigilantius". Las notas de las clases del Kant sobre Metafísica de las costumbres constituyen una joya invalorable, proveyéndonos de gran ayuda a la hora de comprender el sistema kantiano. Louden, Robert, "Vigilantius: moraly for Humans", en Denis, Lara (editora), Kant's Lectures on Ethics. A Critical Guide (Cambridge, Cambridge University Press, 2015), pp. 84-99.

${ }^{12}$ Las RMP es parte del legado manuscrito que nos ha dejado Kant. En él se incluyen "apuntes" o "glosas" hechas sobre los ejemplares que Kant tenía de otros textos, ya sea propios o ajenos, como así también manuscritos conocidos como "hojas sueltas" (löse Blätter). La publicación de los manuscritos formaba parte del plan para llevar a cabo una edición crítica de las obras de Kant. Según el proyecto que W. Dilthey ideó en 1899 y que está recogido en la introducción al primer tomo de los Kant's gesammelte Schriften, dicha edición debía constar de cuatro partes: Obras, Cartas, Legado manuscrito y Lecciones. Más de medio siglo tardó la Academia para que estos escritos fueran publicados. Los textos a los que hacemos referencia se encuentran en el tomo XIX de Kant's gesammelte Schriften publicado en 1934. Según Santos Herceg Según los apuntes que aquí se recogen habrían sido redactados aproximadamente entre 1764 y 1804. Los primeros están fechados aun antes de que Kant presentara su Dissertatio (1770), mientras que los últimos datarían de fechas posteriores a la publicación de la MdS (1797). La mayoría y los más ricos desde el punto de vista del contenido se concentran, no obstante, en el periodo inmediatamente anterior a la publicación de la Crítica de la razón pura $(\mathrm{KrV})(1776-1780)$. SANTos Herceg, José 
(imputatio) en sentido moral es un juicio en virtud del cual alguien es considerado como artífice (causa libera) de una acción, que a partir de entonces se llama hecho (factum) y se somete a las leyes". ${ }^{13}$

La imputación es un juicio que afirma, o en su caso niega, una determinada relación entre dos términos: por un lado un sujeto, el artífice (Urheber), ${ }^{14} \mathrm{y}$ en el otro extremo, la acción (Handlung), ${ }^{15}$ objeto de dicho juico. Dicho de otra manera, el juicio de imputación (Zurechnungsurteil) es un juicio sobre la relación existente entre una acción (Handlung) y un sujeto, considerado Persona (Person). La imputación describe a alguien como 'artífíce' de una acción o sea, como 'causa libera'. La acción es delimitada de los meros sucesos naturales, distinguida como acción libre de una persona. Con ello, la persona y su acción son colocadas en el juicio de imputación en una determinada relación: la acción es imputable a la persona, cuando ésta puede ser considerada artífice de la acción. ${ }^{16}$ Entonces, la imputación describe el acto, nuestro acto, a través del cual comprendemos un suceso como una acción: imputamos así un movimiento corporal o un sonido a un sujeto como acción de una persona. ${ }^{17}$

La imputación en su significado moral pude ser distinguida de la imputación en su significado natural causal: la muerte de una persona puede ser imputable a un fenómeno natural como un laúd, en el segundo de los sentidos, pero nunca en el sentido moral. Lo que distingue a ambas imputaciones es la causa del suceso, la imputación moral representa una relación entre una causa libre (causa libera) y una acción. ${ }^{18}$ La diferencia entre ambas imputaciones es realizada por Kant a partir de un ejemplo

C., "Estudio introductorio", en KANT, Immanuel, Reflexiones sobre filosofía moral (Salamanca, Ediciones Sígueme, 2004), pp. 9-13, pp.17-18.

${ }^{13}$ Kant, Immanuel, (1797) “Die Metaphysik der Sitten”, en KÖNIglich PreußISCHEN AKademie DeR Wissenchaften (editor), Kant's gesammelte Schriften (Berlin, Walter de Gruyter,1907), VI, p. 227

${ }^{14}$ Kant utiliza el término "Urheber" cuya traducción es artífice o autor. Kant no utiliza "Täter", que también corresponde al concepto de autor, aunque este último posee un carácter peyorativo y reservado para designar al autor de un delito. Otros conceptos utilizados por Kant para designar al sujeto imputado son el de "agente" ("Handelnden"), "auctor" o "causa libera".

15 El término "Handlung" para Kant no tenía la connotación con la que hoy se lo conoce, es decir, como proveniente de un sujeto libre. Por el contrario, el término para este autor hace referencia a un mero suceso o evento, fenómenos que hoy se denominan con los conceptos "Vorgang" o "Geschehen". Para la acción libre Kant reserva el concepto de "That" [sic].

${ }^{16}$ BlÖSER, Claudia, cit. (n. 9), p. 13.

17 HruschKa, Joachim, Strukturen der Zurechnung (Berlin, Walter de Gruyter, 1976), p. 13.

${ }^{18}$ BLÖSER, Claudia, cit. (n. 9), p. 14 
que aparece en un pasaje de sus Lecciones sobre filosofía moral, en Kähler, tomando el caso de un borracho afirma, "podemos a un algo atribuir pero no imputar, por ejemplo a un loco o un borracho, sus acciones pueden serle atribuidas pero no imputadas" ${ }^{19}$ Esta distinción entre atribuir (zuschreiben) e imputar (zurechnen), términos equivalentes para la lengua castellana, es realizada por Kant en $\mathrm{RMP}, \mathrm{Al}$ respecto dice,

“(Reflexión 7296) - Factum tribuens no es imputans.

Atribuir - e imputar.

Dado que contemplo algo como un homicidio, atribuyo.

Dado que contemplo algo como homicidio (sub lege), imputo al mismo tiempo la ley" ${ }^{20}$.

Sólo porque la persona es un ser obligado normativamente, le pueden ser imputadas sus acciones. Aquellos que no están alcanzados por la norma, no pueden ser sujeto de la imputación. Así, las manifestaciones de un loco o un borracho no pueden ser consideradas acciones, pues no se originan en una causa libera, como sucede con sujetos adultos sin alteraciones de consciencia. El juicio de imputación implica que la acción se encuentra sometida a leyes, esto quiere decir, que la acción y también la persona, a la que le es imputable la acción, pueden ser valoradas según el baremo de las leyes (sean estas normas éticas o jurídicas). Toda imputación supone un sistema de reglas que tanto el sujeto imputante como el sujeto imputado conocen y emplean. ${ }^{21} \mathrm{La}$ imputación de conductas no sólo implica conocimiento de la norma puesta en discusión sino, al mismo tiempo, posibilidad fáctica de cumplir con el deber deducido de ella. De aquí se desprenden, al menos, dos conclusiones. En primer lugar, toda imputación presupone, necesariamente, que el sujeto pueda cumplir con la norma. Si el sujeto no está alcanzado con por el deber deducido de la norma (función

19 KANT, Immanuel, Vorlesung zur Moralphilosophie, STARK, Werner (editor), (Berlin, Walter de Gruyter, 2004), p. 87, \$125 ff.

${ }^{20}$ Kant, Immanuel, "Reflexionen zur Moralphilosophie", en Preußischen AKADEMIE DER Wissenchaften (editor), Kant's gesammelte Schriften (Berlin-Leipzig, Walter de Gruyter,1934), XIX, p. 305. Kant utiliza indistintamente los verbos zurechnen o imputiren (inexistente en el alemán actual), reservándolos para la adscripción de acciones humanas (imputación moral).

${ }^{21}$ En términos de Hruschka, "En todas nuestras conductas aplicamos reglas, toda nuestra conducta, incluido nuestro idioma, sólo se comprende como la observancia cierta de reglas de conducta predefinidas. También en las actividades libres seguimos reglas, en los silbidos desafortunados ente otras cosas importa la regla de la melodía de la canción, en las suposiciones, la regla que ya constituye esa actividad. HRUSCHKA, Joachim, $S Z$, cit. (n. 17) p. 12. Pese a que Hruschka no cite a Peter Winch, existe un profundo paralelismo entre esta definición planteada y la propuesta por el filósofo del lenguaje. Véase cit. (n. 4). 
directiva de la norma), no le pueden ser imputada la acción. En segundo lugar, el juicio de imputación está estrechamente vinculado al concepto 'libertad'. Sólo acciones libres, pueden ser imputadas.

\section{LA IMPUTACIÓN Y LAS NORMAS: EL CONOCIMIENTO DE LA NORMA COMO PRESUPUESTO DE LA IMPUTACIÓN}

Kant caracteriza la acción como aquella que "se somete a leyes". ${ }^{22}$ Que una acción se someta a las leyes, quiere decir que las leyes contienen un mensaje normativo en relación a esa acción (a saber, ellas prohíben, prescriben o, ante todo, permiten), y que, por lo tanto, la acción puede ser valorada conforme a ellas. El juicio de imputación es también el juicio que distingue una acción como un posible objeto de una valoración a través de leyes. Este juicio, sin embargo, no es comparable con la valoración de la acción (applicatio legis ad factum). La relación entre la acción imputable y la aplicabilidad de leyes puede ser comprendida como una relación de naturaleza bicondicional: por un lado, la imputabilidad de una acción es una condición necesaria para la aplicabilidad de las leyes o, dicho de otro modo, sólo las acciones libres están sometida a leyes. Por otro lado, la imputabilidad también es una condición suficiente para la aplicabilidad de las leyes. Cuando una acción puede ser imputada, está sometida a leyes. Las leyes relevantes pueden ser jurídicas o incluso éticas, ambas caen dentro del concepto general de las leyes morales o sea, "leyes de la libertad". ${ }^{23}$ La imputación moral (moralische Zurechnung) es el concepto general que vale tanto para la imputación conforme a leyes jurídicas como así también conforme a leyes éticas. ${ }^{24}$

Del juicio de imputación kantiano se deducen varias cuestiones. En primer lugar, si la acción está sometida a leyes, solamente puede haber imputación en la medida que el autor esté en condiciones de cumplir con el mandato normativo. De este modo, existe un presupuesto en todo juicio de imputación consistente en el poder cumplir con dicho mandato. En segundo lugar, los juicios de imputación deben ser distinguidos de aquellos cuya finalidad no es la adscripción, sino que se limitan a valorar un determinado fenómeno. En consecuencia, la imputación y la applicatio legis ad factum consisten en procesos normativos diferenciados. En último lugar, la imputación moral, basada en la libertad del Urheber, puede tener lugar a través de la aplicación de normas jurídicas o de normas éticas, di-

\footnotetext{
${ }^{22}$ Kant, Immanuel, $M d S$, cit. (n. 13), p. 227.

${ }^{23}$ Kant, Immanuel, $M d S$, cit. (n. 13), 214.

${ }^{24}$ BlÖSER, Claudia, cit. (n. 9), p. 24.
} 
ferenciándose una y otra, no sólo en el origen de la norma respecto de la cual son valoradas, sino también en sus diversas consecuencias.

Kant, en la Introducción a la MdS, sostiene que "la obligación es la necesidad de una acción libre bajo un imperativo categórico de la razón". ${ }^{25}$ En dicha definición no se encuentra de manera expresa la regla que reza que para poder cumplir con el imperativo categórico de la razón el sujeto debe ser capaz de seguir dicha regla, conocida como la regla "todo deber implica su correspondiente poder" (jedes Sollen impliziert das entsprechende Können!). No obstante su omisión, es posible considerar que en dicha afirmación se halla, de manera implícita, la presunción de que todo sujeto obligado posee también la capacidad de cumplir con su requerimiento. Dado que cuando la razón nos dicta un deber y nos dice que lo apliquemos en la situación concreta, ella también nos dice que podemos cumplirla. Dicho en otros términos, ¿sería capaz la razón de dictarme deberes de imposible cumplimiento? El mismo Kant responde a este interrogante en su conocido escrito Hacia la paz perpetua, en él sostiene que "La moralidad es en sí misma una práctica en el significado objetivo, una unidad de leyes incondicionalmente obligatorias según las que debemos actuar, después de haberle atribuido toda su autoridad a este concepto de deber, es una incoherencia manifiesta decir que no se puede obedecer. En este caso se saldría este concepto, por sí mismo, de la moral (ultra posse nemo obligatur ${ }^{26}$ )" . ${ }^{27}$

El contenido de la regla "deber implica poder" puede analizado tanto desde una perspectiva prospectiva como desde la perspectiva retrospectiva de las acciones que cometemos u omitimos. ${ }^{28}$ Desde la aplicación prospectiva, un determinado deber puede consistir en la obligación de actuar expresado en un mandato (¡debes prestar auxilio!), o bien, en la obligación de omitir mediante una determinada prohibición (¡no matar!). Cuando afirmamos que el sujeto ha infringido el deber, el "deber" (Sollen) de la fórmula deber implica poder no es el deber general de la regla, sino el concreto deber en la aplicación (prospectiva) de la regla en una situación particular. No se trata de la norma por sí misma, sino más bien de la aplicación de la norma la que implica poder. Cuando Kant hace uso del adagio legal "ultra posse nemo obligatur" formula el poder como una condición necesaria

${ }^{25}$ Kant, Immanuel, MdS, cit. (n. 13), p. 222.

${ }^{26}$ Nadie está obligado a nada más allá de su capacidad.

${ }^{27}$ Kant, Immanuel, (1795) "Zum ewigen Frieden. Ein philosophischer Entwurf”, en Königlich Preussischen Akademie der Wissenchaften (editor), Kant's gesammelte Schriften (Berlin-Leipzig, Walter de Gruyter, 1921), VIII, p. 370.

28 Byrd, Sharon; HruschKa, Joachim, Kant's Doctrine of Right (Cambridge, Cambridge University Press, 2010), p. 294. 
para el deber. Sí, el "poder" es una condición necesaria para el "deber", luego el "deber" es una condición suficiente para el "poder". Dicho en otros términos, desde la aplicación prospectiva de la regla "deber implica poder", asumir una obligación significa considerar que la persona obligada es libre de emprender el acto que está obligada a realizar. ${ }^{29}$ La regla prospectiva (¡debes prestar auxilios!, ¡no debes matar!) puede ser reformulada, desde la perspectiva opuesta, en una regla retrospectiva: (iquien fracasa en prestar auxilio en una emergencia violó el sistema relevante de normas! ¡Quién mató a otro lesionó el sistema relevante de normas!”). Luego, la aplicación de esta regla retrospectivamente podría ser formulada como "X actuó ilícitamente". Aplicando retrospectivamente dicha regla implica que la persona (X), a quien la regla le es aplicada, era capaz de seguir los requerimientos de la regla. Esta aplicación corresponde a la implicación en la prospectiva de "deber implica poder" ${ }^{30}$ Es decir, el hecho imputado es contemplado por el sujeto imputante como posible y contingente. Sólo lo posible y contingente, por lo tanto, puede ser imputado. Se sigue de ello, que lo imposible y lo necesario no pueden ser imputados. ${ }^{31}$

Por otro lado, la imputación presupone necesariamente leyes válidas. No se puede imputar a una persona una acción como propia, sin remitirse a las leyes, entonces ¡se debe presuponer su validez? En el modelo kantiano, para que exista un juicio imputación es necesario que las leyes posean validez para la persona, en referencia a la acción considerada. En la dimensión prospectiva, las normas cumplen una función directiva, orientando a los sujetos a adaptar sus acciones conforme al mandato normativo. ${ }^{32}$ Esta función está estrechamente unida con el concepto kantiano de libertad: la libertad señala ahora la capacidad de poder regirse según leyes. Una persona para ser la causa libera de una acción concreta, debe poder, en referencia a dicha acción, regirse de acuerdo a leyes. Por consiguiente, la validez de las leyes es de verdaderamente necesaria para la persona en referencia la acción concreta, para que ella pueda ser considerada artífice de la acción.

${ }^{29}$ Byrd, Sharon, HruschKa, Joachim, cit. (n. 28), p. 296.

${ }^{30}$ Byrd, Sharon, HruschKa, Joachim, cit. (n. 28), pp. 296-297.

31 HruschKa, Joachim, "Imputation”, en Birgham Young University Law Review, volume 1986, Issue 3, (1986), p. 687.

${ }^{32}$ En igual sentido se pronuncia Hruschka quien considera que Kant asume que la ley penal proyecta un efecto, por consiguiente, tiene una finalidad y esta finalidad consiste en apartar a potenciales delincuentes de hechos delictivos. HruschKa, Joachim, "Die, Verabschiedung' Kants durch Ulrich Klug im Jahre 1968: Einige Korrekturen”, Zeitschrift für die gesamte Strafrechtwissenschaft (Berlin, Walter de Gruyter, vol. CXXII, 2010), p. 499. 


\section{LOS NIVELES DE IMPUTACIÓN}

Si bien Kant, al definir a la imputación, no distingue analíticamente entre los diversos niveles que la componen, para una mejor comprensión del sistema de imputación, lo analizaremos a partir de las categorías según las cuales era analizada esta teoría en el siglo xviii, a saber: imputatio facti, applicatio legis ad factum e imputatio iuris. Una vez analizado el modelo de Kant, veremos en cuanto se asemeja o se aleja de las categorías antes señaladas.

\section{Imputación del hecho (imputatio facti)}

El primer juicio de imputación es aquel destinado a concebir un determinado fenómeno como obra de un sujeto. El núcleo del juicio de imputación remite a una especial relación entre una persona y una acción. Esta relación se refleja tanto del lado de la persona, en la medida que ella es señalada como artífice, tanto como del lado de la acción, dado que ésta es denominada "hecho". Dicho con otras palabras, este juicio no sólo conlleva considerar el hecho como obra del artífice sino, simultáneamente, a éste como persona.

En la MdS Kant no se detiene a explicar los conceptos implicados en este primer juicio. Sin embargo, a través de la lectura de la MdS-V, podemos acceder al concepto de Urheber en los siguientes términos: "El autor es un artífice de la acción"33, Kant añade luego: "Artífice significa (...) que en consideración de su fundamento de determinación la acción puede, en sus primeros inicios ser derivada de él. Por lo tanto, él es tratado como la primera causa eficaz. Es decir, el principio de determinación de la acción no puede ser buscado en ninguna otra parte de la naturaleza”. ${ }^{34}$ Por otro lado, la acción (Handlung), en términos de Kant, es un mero suceso acaecido, en el cual un determinado sujeto se ve inmerso. ${ }^{35}$ Con otras palabras, la acción es el mero proceso que el Urheber desarrolla. Dicho concepto de acción no se corresponde con el que es actualmente utilizado como categoría de la teoría del delito, pues este último, está limitado al actuar humanovoluntario. Lo que comprende Kant bajo el concepto "acción” corresponde a lo que hoy entendemos por "suceso" (Geschehen o Vorgang), o - en el caso de acciones de seres vivos - por "comportamiento" (Verhalten). El

${ }^{33}$ Auctor ist ein Urheber der Handlung. Kant, Immanuel, "Metaphysik der Sitten Vigilantius”, en Königlich Preußischen Akademie der Wissenchaften (editor),Kant's gesammelte Schriften. Berlin, Walter de Gruyter, , 1974), XXVII/4-2, p. 558.

${ }^{34}$ Kant, I., $M d S-V$, cit. (n. 33), p. 558-559.

35 HruschKa, Joachim, "Die Würde des Menschen bei Kant", en Archiv für Rechts- und Sozialphilosophie (2002), LXXXIII/ III, p. 447. 
concepto jurídico-penal de acción (Handlung según la doctrina alemana) se corresponde, en lo esencial, con el concepto kantiano de "hecho" (Tat). ${ }^{36}$ Aquello que constituye un hecho, lo aclara Kant, en la Introducción a la MdS "Un hecho recibe el nombre de acción, en cuanto está sometida a las leyes de la obligación, por consiguiente, en cuanto el sujeto en él es considerado según la libertad de su arbitrio". ${ }^{37}$

El paso de la mera acción (Handlung) al hecho (Tat) se produce mediante el primer juicio de imputación que conlleva una valoración, y con ello una transformación, en términos de recreación de la realidad. De esta manera el "hecho" es el resultado de un juicio de atribución mediante el cual se considera el fenómeno acaecido como proveniente de una persona libre. Dicho de otro modo, el hecho no existe como algo previamente dado, sino que surge del mismo proceso de imputación. En el modelo kantiano no existe una realidad, una acción como dato primigenio y carente de valoración previa al hecho.

Kant, en PPP, ${ }^{38}$ define muy bien el ámbito de aplicación del primer juicio de imputación cuando aclara que "Aquí no se trata de la pregunta de si debe ser imputado como mérito o demérito, sino si, en general, debe ser imputado. La imputatio facti se basa en la relación de la acción con una condición práctica, la condición es práctica en tanto ella es una libertad". ${ }^{39}$ El hecho (factum) se funda en la libertad del agente, por ello Kant, en una de sus reflexiones afirma "cuando algo puede ser contemplado como una

36 BLÖSER, Claudia, cit. (n. 9), p. 14.

${ }^{37}$ Kant, Immanuel, $M d S-V$, cit. (n. 33), p. 223.

38 Pertenece a unos de los manuscritos compilados en las Lecciones sobre filosofía moral. Gottlieb Bernhard Powalski comenzó sus estudios en la Universidad Albertina en el año 1777. El manuscrito atribuido a este estudiante, el igual que otro manuscrito sobre geografía física también de su autoría, lleva en su portada un sello redondo color negro con una "P". Sin embargo, las notas sobre filosofía moral no fueron realizadas por Powalski. Al parecer él adquirió estas notas con posterioridad. Según Schwaiger, la portada de este grupo de notas y las de las referidas a geografía física están escritas por la misma mano, pero aquellas pertenecientes a filosofía moral provienen de otra. También aparecen algunas notas marginales escritas con la misma mano con la que se escribió la tabla de contenidos. Quizás, las anotaciones al margen fueron escritas algún tiempo después. Esto refuerza la idea de que las notas sobre filosofía moral no pertenecen a Powalski. Schwaiger, Clemens, "Die Vorlesungsnachschriften zu Kants praktischer Philosophie in der Akademie-Ausgabe", en Kant-Studien (vol. 91, 2000), pp. 185-186. La fecha estimada de su producción no es cierta, se estima que pudo haberse producido en el semestre de invierno de los años 1783-1784.

${ }^{39}$ Kant, Immanuel, "Praktische Philosophie Powalski", en AKademie der WisSENSCHAFTEN DER DDR (editor), Kant's gesammelte Schriften (Berlin, Walter de Gruyter Verlag, , 1974), XXVII/4-1, p. 153. 
acción libre, que según las leyes morales no es necesaria, de tal manera es un factum" ${ }^{40}$

Según Kant, sólo pueden ser imputadas las acciones fundadas en la liberad, pues "la acción es imputada, en la consideración que alguien es libre, o sea no está forzado ni objetiva ni subjetivamente". ${ }^{41}$ En la MdS-V reafirma la idea que en la ejecución de una acción realizada de conformidad al deber impuesto por la norma, el autor sometido a la ley, no es causa libera de su acción. ${ }^{42}$ Por consiguiente, para poder imputar un suceso como factum, Kant tiene en cuenta la norma con la cual la acción es medida. Es decir, la atribución del hecho al Urheber se produce conforme a reglas que tanto el sujeto imputante como el sujeto imputado (Urheber o causa libera) conocen y emplean. Por ello, la norma de conducta funciona en una doble perspectiva, para el Urheber como pauta de conducta válida (función prospectiva) y, para el juez o tribunal, como baremo de medición (función retrospectiva). En este primer juicio de imputación existe un proceso circular, un ir y venir entre la ley y el hecho. Kant es consciente de este proceso en la medida que afirma "en la determinación de las circunstantiarium in facto, para encontrar los momenta in facto es ya necesario tomar en consideración la ley, puesto que, si bien la ley todavía no se imputa, contribuya a la total fijación del factum mismo". ${ }^{43}$

Hasta el momento el juicio de imputación al hecho todavía no contiene ninguna valoración sobre la acción o sobre la persona, sino que identifica a una persona como libre artífice de la acción. A través del juicio de imputación la acción la acción es señalada como una acción que está sometida a leyes, y con ello es un posible objeto de valoración. ${ }^{44}$ El juicio del primer nivel de imputación es, luego, un juicio que incluye una unidad de elementos adscriptivos y descriptivos. De la multiplicidad de factores existentes, determinados factores particulares son seleccionados y, en vistas de la venidera aplicación particular de la ley en cuestión, son interpretados como hecho relevante. La imputación ocurre a la luz de la ley aplicable de la cual ciertas circunstancias son relevantes y otras circunstancias son (todavía) irrelevantes. El juicio de imputar un evento o su no realización a un individuo como un "hecho" tiene el propósito de hacerlo idóneo para la aplicación de la ley (applicatio legis ad factum) ${ }^{45}$

\footnotetext{
${ }^{40}$ Kant, Immanuel, RMP, cit. (n. 21), Refl. n. 6783, p. 159.

${ }^{41}$ Kant, Immanuel, $R M P$, cit. (n. 21), Refl. n. 6777, p. 157.

${ }^{42}$ KANT, Immanuel, $M d S$ - $V$, cit. (n. 33), p. 560.

${ }^{43}$ Kant, Immanuel, $M d S$ - $V$, cit. (n. 33), p. 563.

44 BlÖSER, Claudia, cit. (n. 9), pp. 40-41.

${ }^{45}$ HruschKa, Joachim, Imputation, cit. (n. 31), p. 683.
} 
a) Imputación y persona.- Es a través del primero de los juicios de imputación mediante el cual el agente es considerado persona. Dicho en otros términos, el concepto de persona surge del propio proceso imputativo en la medida en que el sujeto es reconocido como el artífice del hecho, o lo que es lo mismo, su consideración como "causa libera". Para Kant un sujeto sólo es libre, cuando está sometido a normas, que el mismo se ha dado o sea, que las reconoce como propias. La condición de la libertad en la definición de la imputación remite a otras circunstancias, que deben ser cumplimentadas; en la medida en que una acción es imputable, el sujeto será contemplado como "causal libera" de ella. Esto quiere decir, que el sujeto no sólo posee, en general, una voluntad libre, sino que la acción, cuya imputabilidad está en cuestión, posee la capacidad de ser ejecutada de conformidad con las leyes relevantes. ${ }^{46}$

Kant considera a la persona como centro de imputación; toda causa libera tiene, según el planteamiento kantiano, su origen en la persona humana. Sólo las personas pueden ser pasibles de imputación, puesto que en el acto mismo de imputación se afirma su libertad. Como criterio diferenciador entre personas y cosas, Kant utiliza el punto de vista de la imputabilidad de las acciones, ${ }^{47}$ así "Una cosa es lo que no es susceptible de ninguna imputación. Todo objeto del libre arbitrio, que carece de libertad por sí, se llama, pues, cosa (res corporalis)". ${ }^{48}$ Para el filósofo de Königsberg, persona y ser humano no son términos equivalentes, ${ }^{49}$ puesto que no todo ser racional es considerado persona. Según su esquema, la imputación implica libertad y la libertad autonomía. Persona es todo sujeto autónomo, todo aquel que se dicte su propia norma moral (autolegislador). El carácter de persona se

46 BlÖSER, Claudia, cit. (n. 9), pp. 16-17

${ }^{47}$ Ninguna acción moral sin libertad e imputación es posible, pero la libertad es sólo una cualidad negativa del deber ser, la imputación primeramente es una cualidad dinámica positivamente generadora del deber ser. STOCKHAMMER, Morris, Kants Zurechnungsidee und Freiheitsantinomie (Köln, Kölner Universitäts Verlag, 1961), p. 311.

${ }^{48}$ Kant, Immanuel, $M d S$, cit. (n. 13), pp. 223-224.

${ }^{49}$ La doble naturaleza del hombre, una empírica y otra inteligible, ya había sido resuelta en la tercera antinomia de la Crítica de la razón pura, no resultando para Kant contradictoria. Los dos principios que gobiernan al hombre son independientes el uno del otro y, por tanto, no se afectan ni se contradicen. El hombre, en tanto perteneciente al mundo sensible, es un objeto sometido a la causalidad. Por el contrario, el sujeto en tanto ser inteligible, se concibe como libre. De esta manera, el sujeto, en su carácter inteligible en tanto agente de un conjunto de fenómenos, no estaría él mismo determinado por ninguna condición que afecte a éstos, ya sea temporal, espacial, etc., aunque "su efecto aparezca en un fenómeno". KANT, Immanuel, (1781) Kritik der reinen Vernunft (Stuttgart, Reclam, 2013), p. B 567/A 539. 
afirma imputando responsabilidad al sujeto por su obrar. El concepto de persona presupone el de libertad. La asunción de que una acción es libre es un acto de imputación. La libertad misma no es más que la capacidad de imputación (receptivitas imputationis). El sujeto obra de manera libre en la medida que se desvincula del mundo sensible; la libertad se constituye así en el fundamento del actuar del sujeto en tanto homo noumenon. La libertad en Kant no es un concepto de la experiencia, ni puede serlo, ${ }^{50}$ sino que se presenta como una experiencia necesaria que debe presuponerse. ${ }^{51}$ Kant niega que podamos probar teoréticamente que somos libres o incluso comprender cuánta libertad es posible. Debemos presuponer que, en tanto seres racionales, somos libres. ${ }^{52}$ Por otro lado, no hay contradicción entre la proposición que dice que los seres racionales son libres y la proposición que nuestras acciones en el mundo de los sentidos están determinadas de acuerdo con las leyes de la naturaleza. ${ }^{53}$ Así, la causalidad de la libertad, que posibilita la imputación, presupone la causación empírica de un efecto, puesto que la libertad es sólo una idea de la razón, cuya realidad objetiva es en sí misma dudosa, mientras que la naturaleza, por el contrario, es un concepto del entendimiento que demuestra su realidad, y ello de un modo necesario, en ejemplos de la experiencia. De este modo, la capacidad física de obrar es condición de la imputación y lo único que podemos probar a través de la experiencia es la presencia de impedimentos del orden de lo natural que conlleven la negación de la libertad.

b) La capacidad de imputación o imputabilitas. - Kant coloca junto al juicio de imputación el grado de imputabilidad en función de la cual una acción puede ser imputada a su autor en mayor o menor medida. Así, "El grado de imputabilidad (imputabilitas) de las acciones debe estimarse subjetivamente, teniendo en cuenta la magnitud de los obstáculos que ha

${ }^{50}$ A diferencia de la libertad trascendental que debe darse por supuesta, "La libertad práctica puede demostrarse por experiencia...” KANT, Immanuel, $K r V$, cit. (n. 49), p. B830/A802.

${ }^{51}$ Llanos Cifuentes, Alejandro, Fenómeno y trascendencia en Kant (Pamplona, Universidad de Navarra, 2002), p. 130.

52 En palabras de Kant: "Como ser racional y, por tanto, perteneciente al mundo inteligible, el hombre nunca puede pensar la causalidad de su propia voluntad más que bajo la idea de libertad, pues ésta no es otra cosa que la independencia de las causas determinantes del mundo sensible (independencia que siempre debe atribuirse a sí misma la razón)” KANT, Immanuel, (1785) “Grundlegung zur Metaphysik der Sitten”, en Königlich Preussischen Akademie der Wissenchaften (editor), Kant's gesammelte Schriften, Berlin, Walter de Gruyter,1903), IV p. 452.

53 Wood, Allen, Kantian Ethics (Cambridge, Cambridge University Press, 2008), p. 130. 
habido que vencer" 54 . De este modo, el término "imputabilitas" (Zurechnungsfähigkeit) designa, no la moralidad sino la posibilidad de atribución concreta de la acción y del hecho. La imputabilidad determina en definitiva, la posibilidad de someter a juicio la acción del artífice. En la MdS Kant establece solamente la gradación de imputabilitas, pero no desarrolla casos de exclusión de la misma. Sin embargo, mediante el análisis de las Lecciones, Kant sí reconoce casos en que la imputabilidad desaparece. En la MdS-V Kant aclara que solamente son imputables aquellas consecuencias que se originan en la libertad del agente. ${ }^{55}$ Por lo tanto, ella falta cuando se trata de acciones de un sujeto no libre. Algunas causales de exclusión de la imputabilidad, son tratadas por Kant en PPP. Por un lado, falta la imputabilitas cuando el sujeto actuante es un incapaz. Kant define al incapaz como un sujeto delirante o un niño menor de edad, y lo que este incapaz haga no le puede ser imputado. ${ }^{56}$ Por otro lado, cuando se trata de eventus inevitabiles, aquellos sucesos que superan el poder de un hombre, o bien porque el hombre no pudo preverlos, o bien, porque él no ha podido evitarlos. Kant dice al respecto: “...para todas estas circunstancias valen la regla: ultra posse nemo obligatur, y ellas no son imputables". ${ }^{57}$ En suma, en estos casos Kant plantea una exoneración del autor, constituyendo casos de incapacidad de imputación (Zurechnungsunfähigkeit $\left.{ }^{88}\right) .^{59}$ En el modelo kantiano, el concepto de inimputabilidad e incapacidad de acción se identifican. La imputabilidad está en estrecha relación con la imputación al hecho, pues quien es imputable no está alcanzado por la norma de conducta, eliminando ya la imputación de primer nivel. Muchas de las causas de exclusión de la culpabilidad (imputación de segundo nivel) son tratadas por Kant como casos de ausencia de acción, equiparando la inevitabilidad de las acciones con supuestos de alteración de la consciencia.

Cuando se señala a una persona capaz de imputación, no contiene todavía ninguna valoración de sus acciones o sobre él mismo. Sólo se dice con ello que sus acciones, en principio, pueden ser imputadas. La capacidad de imputación corresponde a una persona, entonces, independientemente

${ }^{54}$ Kant, Immanuel, $M d S$, cit. (n. 13), p. 228.

55 Kant, Immanuel, $M d S-V$, cit. (n. 33), p. 563.

${ }^{56}$ Kant, Immanuel, PPP, cit. (n. 39), p. 176.

57 Kant, Immanuel, $M d S-V$, cit. (n. 33), p. 563.

58 "Zurechnungsunfähigkeit" es el concepto en alemán antiguo equivalente al de inimputabilidad en castellano, hoy en día se utilizan en alemán su equivalente " $U n$ zurechnungsfähigkeit" o bien, "Schuldunfähigkeit" que se traduce como incapaz de culpabilidad.

59 PAWLIK, Michael, Das Unrecht des Bürgers. Grundlinien der Allgemeinen Verbrechenslehre (Tübingen, Mohr Siebeck, 2012), p. 229. 
de acciones aisladas, fundada en determinadas propiedades o sea, capacidades. Kant identifica a ésta con la libertad trascendental. La capacidad de imputación y la imputación al hecho están, por consiguiente, unidas: la imputación al hecho expresa, que una persona es imputable. ${ }^{60}$

La imputabilitas en tanto presupuesto de la imputación al hecho, permite ser valorada de manera gradual. Kant describe dos reglas respecto al grado de imputabilidad de acciones. La primera reza: "Cuanto mayor es el obstáculo físico (que proviene de la sensibilidad) y menor la resistencia moral (que proviene del deber), tanto más meritoria es la acción buena. Por ejemplo, si con gran perjuicio mío libro a mi enemigo capital de un peligro eminente". Y la segunda, "cuanto menor es el obstáculo físico, y cuanto mayor es el que resulta de los principios del deber, tanto más imputable como falta es la transgresión. - El estado del alma ocasiona, pues, una diferencia en la imputabilidad, según que el sujeto ha cometido la acción en el momento de la pasión o con plena tranquilidad". ${ }^{61}$

Existen dos tipos diversos de obstáculos, los naturales como barreras en el mundo sensible, en tanto que los deberes son barreras morales en el mundo inteligible. ${ }^{62}$ Como bien sostiene Joerden, se torna problemático en el referido pasaje de Kant la alusión "obstáculo moral", en referencia al deber, dado que permanece de momento oscuro, por qué en la ejecución de una acción moral se debe tratar de la superación (Überwindung) de un obstáculo de tal naturaleza. ${ }^{63}$ Las fórmulas de Kant antes mencionadas se tornan comprensibles, según Joerden, no cuando el concepto de obstáculo, como en principio el propio Kant con sus propias palabras parece suponer, se refiere siempre a la ejecución de la acción en cuestión, sino cuando se aclara, respectivamente, si se trata de un obstáculo en referencia a la ejecución o bien, de un obstáculo con respecto a la omisión de la respectiva acción. Aquí cambia el punto de vista rector al interior de la fórmula para la conducta meritoria, del igual modo que al interior de la fórmula para el hecho culpable. En primer lugar, este cambio torna también comprensible, por qué en una fórmula la magnitud de los obstáculos respectivos deben ser directamente proporcionales al grado de la imputación, mientras que en la otra, sin embargo, deben ser inversamente proporcionales al mencionado grado. Si se quiere evitar esta vaguedad en ambas fórmulas originales de Kant, es necesaria una reformulación en la que el punto de referencia de los obstáculos tome en consideración el cambio en el modo

${ }^{60}$ BlÖSER, Claudia, cit. (n. 9), p. 42.

${ }^{61}$ Kant, Immanuel, $M d S$, cit. (n. 13), p. 228.

${ }^{62}$ Byrd, Sharon, HruschKa, Joachim, cit. (n. 28), p. 209.

63 Joerden, Jan, "Zwei Formeln in Kants Zurechnungslehre", en Archiv für Rechts- und Sozialphilosophie (1991), p. 528. 
de comportamiento. ${ }^{64}$ Joerden sugiere que la primera de las fórmulas debe, entonces, decir: "Cuanto mayor el obstáculo físico (de la sensibilidad) para la ejecución de la acción y menor la resistencia moral (del deber) para su omisión, tanto más es valorado el buen hecho al mérito" Y la segunda fórmula debe rezar: "cuanto menor el obstáculo natural para la omisión de la acción y mayor el obstáculo por razones de deber para su ejecución, tanto más es imputada (como culpable) la trasgresión". ${ }^{65}$

\section{La applicatio legis ad factum}

Las leyes (reglas de conducta, en la terminología de Hruschka) y las reglas, según las cuales una acción puede ser imputada (reglas de imputación), deben ser distinguidas. ${ }^{66}$ Las reglas de conducta por un lado, y las reglas de la imputación por otro, poseen una diversa relación temporal en relación a la acción: una norma de conducta, al mismo tiempo es una regla prospectiva, cumpliendo una función directiva, es decir, indicado a una persona que debe hacer u omitir, o, en su caso, que le está permitido (función de prevención general), y es una regla retrospectiva, para la instancia en que la acción es valorada según el tenor de la norma (applicatio legis ad factum). Esta instancia puede ser hecha por el propio agente o por otra persona. Por el contrario, las reglas de la imputación son sólo aplicables retrospectivamente a la persona imputable por el sujeto imputante; se imputan acciones, que yacen en el pasado. ${ }^{67}$

La actividad de aplicación de la ley al hecho (applicatio legis ad factum) consiste en determinar si la conducta del sujeto se ajusta a lo debido, o bien, si ella se ubica por debajo o por encima de lo que exige la ley. Esta actividad de medición es independiente de la atribución del hecho (imputatio facti), aunque ambas pueden operar en simultáneo, puesto que la norma cumple una función de recorte de los hechos a imputar. La ley da el estándar para la determinación de qué hechos, ante bajo qué circunstancias, deben ser seleccionados para el primer nivel de imputación. ${ }^{68}$ La relación del hecho y la norma, que sirve como baremo de valoración (norma de conducta en su función retrospectiva), puede adoptar los siguientes matices: puede ser "más de lo que la ley requiere" (meritorio), "menos de lo que la ley requiere (demerito), o "exactamente lo que la ley requiere" (debido). Si la

${ }^{64}$ JOERDEN, Jan, ARSP, cit. (n. 63), pp. 530-531.

65 JoErden, Jan, $A R S P$, cit. (n. 63), p. 537.

${ }_{66}$ Véase, HRuschKa, Joachim: "Verhaltensregeln und Zurechnungsregeln", en Rechtstheorie. Zeitschrift für Logik, Methodenlehre, Kybernetik und Soziologie des Rechts (1991), XXII, pp. 449-460.

${ }^{67}$ BLÖSER, Claudia, cit. (n. 9), p. 24.

${ }^{68}$ HruschKa, Joachim, Imputation, cit. (n. 31), 685. 
acción se ajusta a lo debido, no hay imputación alguna. Especial atención merecen aquellas acciones que, o bien, producen más de lo que la ley exige, o bien permanecen por debajo de lo exigido por la ley dado que en ellas, y sólo en ellas, se reacciona con una retribución, sea ahora a través de una recompensa o a través de una pena. ${ }^{69}$ Sólo una vez valorado el hecho, en la medida que el mismo no concuerde que con lo exigido por el deber, se procederá a la imputación de segundo nivel (imputatio iuris).

Está sujeto a discusión si Kant reconoce este estadio valorativo de manera independiente a los juicios imputación. En la MdS Kant parece insinuar la distinción entre la acción de imputar y la de valorar el hecho conforme a la ley (applicatio legis ad factum) cuando sostiene que "Lo justo o lo injusto (rectum aut minus rectum) es en general un hecho conforme o no con el deber (factum licitum aut illicitum)" ${ }^{70}$ En el caso del factum licitum, el sujeto realiza el hecho conforme al deber y, por tanto, el hecho es considerado "debido". En el caso del factum illicitum, por el contrario, el hecho no se adecua al deber. Es en relación a este segundo grupo de casos respecto de los cuales se plantea la posibilidad de realizar un segundo juicio de imputación (imputatio iuris). El hecho de confrontar la acción con la norma en cuestión, es la actividad propia de la aplicación de la ley al hecho. En este pasaje, Kant no está atribuyendo un fenómeno como hecho, o sus consecuencias como meritorias o demeritorias, sino que sólo está midiendo el hecho con la norma en cuestión, y esta es la actividad propia de la applicatio legis ad factum.

Hruschka, por su parte, considera que Kant en la MdS ya demuestra conocer con total exactitud la distinción que existe entre justificación -propia de la applicatio legis ad factum-y exculpación-perteneciente a la imputatio iuris-. Dicho argumento lo funda en la interpretación del pasaje referido al Derecho de necesidad (ius necessitatis)..$^{71}$ Según este autor, Kant en dicho

69 JoERdEn, Jan, ARSP, cit. (n. 63), p. 526.

${ }^{70}$ KanT, Immanuel, $M d S$, cit. (n. 13), pp. 223-224.

71 "Este pretendido derecho consiste en la facultad moral de defender mi vida, dando muerte a quien no me hace daño. Es evidente que aquí debe haber un conflicto del derecho consigo mismo, porque no tratemos aquí del agresor injusto que atenta a mi vida, del que me defiendo matándole (jus inculpatae tutelae), caso en el cual la recomendación o moderación (moderarem), no corresponde siquiera al derecho sino a la moral; sino que se trata de la violencia lícita contra el que no la ha usado conmigo, lo cual es prohibido por el derecho positivo. Claro es que esta aserción no debe entenderse objetivamente, según el mandato de una ley, sino sólo en el sentido subjetivo, y tal como se pronunciaría la sentencia en justicia. En efecto no puede haber ninguna ley penal que condene a muerte a aquel que, naufragando con otro y corriendo el mismo peligro de perder la vida, le rechaza, apoderándose de la tabla con cuyo auxilio hubiera podido salvarse; porque la pena impuesta por la ley al que 
fragmento establece una diferenciación entre justificación y exculpación. De las afirmaciones de Kant se desprende que un hecho cometido en legítima defensa "no merecería pena" (unsträflich), traduciendo la palabra latina "exculpatio"72 como causal de justificación. Por consiguiente, un autor que obra en legítima defensa estaría justificado (exculpatio). Por el contrario, en el caso de Carnéades, el autor no está amparado por exculpatio alguna, siendo su autor un "factum culpabile". Pero en este caso el autor gozaría del beneficio de un argumento cuyo efecto es el mismo al de una causa de justificación. ${ }^{73}$ Kant define a la permisión de la siguiente manera "Una acción que no es mandada ni prohibida, es simplemente permitida, porque respecto de ella no hay ley que se imponga a la libertad (facultad moral, derecho) y por tanto no hay deber. Una acción de esta especie se llama moralmente indiferente (indifferens, adiaphoron, res merae facultatis)".${ }^{74} \mathrm{De}$ acuerdo a la interpretación que hace Hruschka del concepto "justificación" según Kant, éste debe entenderse objetivamente formando parte de aquello que una ley prescribiría. Al término "prescribir" (Vorschreiben) lo entiende en sentido amplio, abarcando no sólo las prohibiciones y prescripciones sino también las permisiones legales. Así, toda ley permisiva le corresponde desde el punto de vista ex post (perspectiva retrospectiva) una causa de justificación. Sin embargo, este paralelismo no sería posible en las causas de exclusión de la culpabilidad, puesto que este tipo de excepciones se hallan fuera del sistema de reglas del derecho (sistema de prescripciones, prohibiciones y permisiones), ${ }^{75}$ las causas de la imputación de segundo

despojara al otro de la tabla salvadora, nunca podía ser mayor que la pérdida de la vida. Semejante ley penal no tendría fuerza alguna represiva; porque la amenaza de un mal todavía inseguro (la muerte por sentencia del juez) no puede igualar al tenor de un mal seguro (el de perecer ahogado). Por consiguiente, el hecho de la conservación mediante la violencia, no debe ser considerado como inocente (inculpabile), es cierto, sino únicamente como incastigable (impunibile)". KANT, Immanuel, $M d S$, cit. (n. 13), pp. 235-236.

${ }^{72}$ Kant utiliza el término "exculpation" como causas de justificación y el término "excusatio" como causas de exculpación, o sea, causales que no eliminan la ilicitud de la conducta sino sólo dispensan de pena.

73 HruschKa, Joachim, "Rechtfertigungs- und Entschuldigungsgründe: Das Brett des Karneades bei Gentz und bei Kant", en Goltdammer's Archiv für Strafrecht (1991), pp. 8-9.

${ }^{74}$ Kant, Immanuel, $M d S$, cit. (n. 13), p. 223.

75 Conforme al hexágono deontológico, Hruschka considera a las eximentes como la oposición de contravalencia (excepciones) de las prescripciones así como las permisiones lo son respecto de las prohibiciones. Véase, HRUSCHKA, Joachim, "Das deontologische Sechseck in der Jurisprudenz", en Recht der Wirtschaft und der Arbeit in Europa. Gedächtnisschrift für Wolfgang Blomeyer (Berlin, Dunker \& Humblot, 2010), pp. 780-784. 
nivel forman un sistema de reglas propio. ${ }^{76}$ Ante estos hechos la ley penal no cumple ningún efecto disuasorio, por lo tanto, sería absurdo penar al sujeto por un hecho cometido ante estas circunstancias, con lo cual este hecho queda como impune (factum impunibile). ${ }^{77}$ Fundado en estos argumentos, Hruschka entiende que las causas de justificación pertenecen a la valoración del hecho conforme a la norma (applicatio legis ad factum), no siendo estrictamente un juicio de imputación sino sólo una valoración del hecho previamente atribuido al Urheber (imputatio facti) conforme a un baremo (la norma de conducta desde la perspectiva ex post)..$^{78} \mathrm{El}$ caso de Carnéades, sin embargo, no sería más que un supuesto en el que no se puede realizar un juicio de reproche y, por lo tanto, decae el segundo nivel de imputación. ${ }^{79}$

A través de la lectura de la obra no publicada por el propio Kant es posible inferir que este autor distingue la imputatio facti de la applicatio legis ad factum, aunque confunde esta última con la imputatio iuris. Puesto que en una sola operación mide el suceso imputado como hecho con la ley respectiva e imputa las consecuencias. ${ }^{80} \mathrm{~A}$ ambas operatorias denomina "imputatio legis", ${ }^{81}$ En la MdS-V Kant afirma que "La imputatio legis es,

${ }^{76}$ Según Hruschka la distinción efectuada por Kant entre los facta imputabile y los facta impunibilia se basa, desde el punto de vista histórico, en la distinción formulada por Daries entre exceptiones secundum y exceptiones contra leges institutae. HrusChKA, Joachim, GA, cit. (n. 73), pp. 9-10.

77 HruschKa, Joachim, GA, cit. (n. 73), p. 10.

${ }_{78}$ Véase, HruschKa, Joachim, Rechtstheorie, cit. (n. 66), pp. 449-460.

${ }^{79}$ Casos en que el sujeto en la ejecución de la acción (a pesar del conocimiento de la regla en cuestión) está impedido de seguir esa regla, HRUSCHKA, Joachim, SZ, cit. (n. 17), p. 44.

${ }^{80}$ En igual sentido se interpretación se pronuncia Sánchez-Ostiz quien sostiene que cuando Kant menciona hace uso de los conceptos imputatio facti e imputatio iuris los utiliza de una manera incorrecta habiendo una confusión entre la medición del hecho con arreglo a la ley y su imputación a título de mérito o de demérito, esto es, respectivamente la applicatio legus ad factum y la imputatio iuris. SÁnchez-Ostiz, Pablo, Imputación y teoría del delito. La teoria kantiana de la imputación y su recepción en el pensamiento jurídico-penal contemporáneo (Buenos Aires, B de F, 1998), p. 106.

${ }^{81}$ Para Hruschka, Kant utiliza las obras de Achenwall y Baumgarter como base de sus clases y de hecho, la terminología latina en las notas de las clases Vigilantius se originan primariamente de esos autores. Ambos autores, pero aún más Baumgarter, distinguen entre imputación de un acto (imputatio facti) e imputación de la ley (imputatio legis). Para Hruschka, este segundo juicio de imputación consiste, según Kant, en el acto de imputación de la ley es la aplicación de la ley a ese hecho, o la subsunción del acto bajo la ley. HruschKA, Joachim, "On the logic of imputation in the Vigilantius lecture notes”, en Denis, Lara (editora) Kant's Lectures on Ethics. A Critical Guide (Cambridge, Cambridge University Press, 2015), pp. 170-171. 
entonces, la applicatio legis ad factum bajo la ley (sub lege sumtum)" ${ }^{82}$ En esa definición Kant circunscribe la función de la aplicación de la ley al hecho a su ámbito específico. Sin embargo, en PPP confunde esta actividad con la imputatio iuris, en la medida que afirma que "la imputatio legis en la comprensión jurídica es la applicatio legis ad factum" 83 , o bien, cuando reza que "La imputatio legis es la aplicación de la ley, ya sea como mérito o como demérito" ${ }^{84}$ Más adelante reafirma dicha confusión, cuando aclara que "La imputación tiene dos Juicios: 1.Si trato la imputación como una acción libre, se llama pues imputatio facti. 2. Si trato la imputación en relación a una ley o sim al mismo tiempo, la aplico como una ley sobre la acción, se llama pues imputatio legis". ${ }^{85}$

\section{La imputación de segundo nivel (imputatio iuris)}

La imputatio iuris es el segundo juicio de imputación consistente en la atribución del hecho valorado a título de "mérito" o de "demérito", en el caso de la imputación moral, o de imputación a título de "recompensa" o "culpabilidad", en el ámbito de la imputación jurídica. Este juicio de imputación, presupone la imputación al hecho -y con ella, la capacidad de imputación (imputabilitas)-, como así también la applicatio legis ad factum. Todas ellas son condiciones necesarias para la imputación de las consecuencias. $^{86}$

Que la acción valorada sea imputada al sujeto, implica una valoración positiva o negativa de la persona fundada en su acción. Cuando la valoración a través de la ley fue negativa, pues ha hecho menos de lo que la ley exige, es imputada la acción del sujeto a la culpabilidad. Cuando, por el contrario, la valoración de la acción fue positiva, ella es imputada al mérito. ${ }^{87}$

Kant no reconoce analíticamente este juicio como independiente puesto que confunde la actividad de aplicación de la ley al hecho con la imputación de las consecuencias. Kant ve en la applicatio legis ad factum no sólo una condición necesaria para la imputación de segundo orden (imputatio iuris), sino también una condición suficiente. Una vez medido el hecho, si el mismo se encuentra por encima o por debajo de lo que la ley exige, deben serle imputadas las consecuencias. Si bien en la $\mathrm{MdS}$ no hace alusión expresa a los diversos niveles analíticos de la imputación, si

\footnotetext{
${ }^{82}$ Kant, Immanuel, $M d S-V$, cit. (n. 33), p. 562.

${ }^{83}$ Kant, Immanuel, PPP, cit. (n. 39), p. 159.

${ }^{84}$ Kant, Immanuel, PPP, cit. (n. 39), p. 153.

${ }^{85}$ Kant, Immanuel, PPP, cit. (n. 39), p. 154.

${ }^{86}$ BLÖSER, Claudia, cit. (n. 9), p. 41.

87 BLÖSER, Claudia, cit. (n. 9), p. 41.
} 
realiza esta distinción en las anotaciones hechas al texto de Baumgarten, ${ }^{88}$ como así también en el desarrollo de la teoría de la imputación que Kant realizaba en las Leccion es. Al primer juicio lo denomina "imputatio facti", al segundo "imputatio legis", comprendiendo esta última la valoración del hecho y la imputación de las consecuencias.

Kant traza un paralelismo entre los presupuestos para la imputación de las buenas consecuencias, imputación meritoria o supererogatoria y los presupuestos de la imputación demeritoria o imputación a título de reproche. Este paralelismo existente entre ambos tipos de imputación está mediado por la diferencia existente entre el actuar moral y el actuar jurídico, puesto que conforme al primero el sujeto sólo actúa siguiendo el deber moral, en el caso del derecho el autor actúa por móviles diversos al deber (coacción) es decir, los incentivos para acatar la norma son fijados por el sistema de coacción estatal ${ }^{89}$. Si bien Kant divide la MdS en la MdS-R y la MdS-T, el núcleo de la relación entre ambas teorías consta de dos aspectos. El primero, ambas teorías pueden ser derivadas del imperativo categórico. Esta derivación, en caso de la ley, no implica ningún debilitamiento de la moralidad: la obligación moral permanece idéntica. ${ }^{90} \mathrm{El}$ segundo, la diferencia entre ambas teorías yace en los motivos de su respectiva comisión. Un determinado hecho puede ser objeto de legislación jurídica o de auto-legislación pudiendo ser idéntico el contenido del precepto pero se distinguen en la característica del incentivo. ${ }^{91}$ La ejecución de la Teoría del derecho sólo tiene que lidiar con la coerción como su motivación, mientras la Teoría de la virtud es responsable por la ejecución por el puro deber. ${ }^{92}$

${ }^{88}$ Véase, KANT, Immanuel, "Erläuterungen zu A. G. Baumgartens. Intia Philosophiae practicae Primae", en Preußischen Akademie Der Wissenchaften (editor), Kant's gesammelte Schriften, Berlin-Leipzig, Walter de Gruyter,1934), XIX, pp. 6181.

${ }^{89}$ En la $M d S-R$ Kant utiliza el siguiente concepto de derecho: "El derecho es el conjunto de condiciones bajo las cuales el arbitrio de uno puede ser unificado con el arbitrio del otro según una ley general de la libertad". Kant, Immanuel, $M d S$, cit. (n. 13), pp. 380-381).

${ }^{90} \mathrm{El}$ área del derecho abarca todo deber moral que también puede ser cumplido por deber. En otras palabras, el derecho debe facilitar el cumplimiento de todo deber moral que puede ser cumplido a través de la coerción por la coerción misma (esto es, a través de la amenaza de la coerción y de la aplicación de la coerción). MERLE, Jean-Christophe, German Idealism and the Concept of Punishment (New York, Cambridge University Press, 2009), p. 28.

${ }_{91}$ PоттеR, Nelson, "Kant on Obligation and Motivation in Law and Ethics" Jahrbuch für Recht und Ethik, (1994), II, p. 94.

${ }^{2}$ Merle, Jean-Christophe, cit. (n. 89), p. 27. Esta dicotomía ha sido seguida por la tradición germánica en la que el derecho habla de cuestiones jurídicas y la mo- 
En la Introducción a la MdS, al tratar el concepto de imputación, Kant afirma que "El mérito (meritum) consiste en hacer algo conforme al deber, además de lo estrictamente exigible por la ley. Si no se hace más de lo prescrito por la ley, no hay más que el pago de una deuda (debitum); pero, si se hace menos, hay delito moral, demérito (demeritum). El efecto jurídico del delito es la pena (poena), el de una acción meritoria es la recompensa (proemium), suponiendo que la recompensa prometida en la ley haya sido la causa de la acción. La conformidad con el deber (debitum) no tiene efectos jurídicos, - la retribución gratuita (remuneratio s. repensio benédica) no guarda relación jurídica con una acción”. De este pasaje se derivan dos sistemas diversos de imputación, el ético y el jurídico respectivamente, que además de estar fundados en motivaciones diversas, también difieren en sus consecuencias.

En la imputación ética el hecho puede ser atribuido a título de mérito o a título de demérito. Kant define al mérito al tratar el concepto de imputación en los siguientes términos: "El mérito (meritum) consiste en hacer algo conforme al deber, además de lo estrictamente exigible por la ley". ${ }^{93}$ En la MdS-T, por su parte, Kant vuelve a tratar el mérito del hecho de una manera parcialmente diversa al concepto reproducido anteriormente. Al respecto afirma que "los deberes imperfectos son, así, meros deberes de virtud. Su cumplimento es meritorio (meritum) $=+a$; mientras que su transgresión no es demérito (demeritum) = -a, sino sólo carencia de valor moral $=0$, salvo que fuera un principio para el sujeto no someterse a aquellos deberes" ${ }^{94}$ En este tipo de imputación, los hechos que sean correctos, como también los que excedan del deber, se imputan a título de mérito (meritum), puesto que el hecho se ha realizado siguiendo el deber moral; en estos casos el autor ha realizado una actuación ética dado que el autor se ha impuesto a sí mismo un deber moral. Por el contrario, los que quedan por debajo del deber, son considerados demeritorios, puesto que "cualquier acción contraria al deber se llama transgresión (peccatum)" ${ }^{95}$ Kant clama que en aquellas ocasiones en las que estamos moralmente obligados a hacer algo, debemos hacer lo que es moralmente requerido por el sólo motivo de la obligación. El fracaso en hacer esto implica, luego un tipo de error - un

ralidad de la cuestión del deber. Sin embargo, como señala Fletcher, en la tradición de habla inglesa la moralidad tiene un sentido más amplio, incluso a veces ilimitado, siendo dicha línea de división difusa. FletCher, George, Gramática del Derecho penal (traducción castellana de Francisco Muñoz Conde, Buenos Aires, Hammurabi, 2008), p. 264.

${ }^{93}$ SÁnchez-Ostiz, Pablo, cit. (n. 80), p. 227.

${ }^{94}$ Kant, Immanuel, $M d S$, cit. (n. 13), p. 390.

95 Kant, Immanuel, $M d S$, cit. (n. 13), p. 390. 
error del tipo que indica un mal moral (moralische Böse).${ }^{96}$ En esta clase de imputación, al estar fundada en el deber moral, carece de la coacción; por lo tanto, no hay posibilidad de atribuir el hecho a título de demérito ya que se carece de lo único que fundamenta este tipo de imputación, que no es otra cosa que el deber moral que se autoimpone el sujeto; los deberes jurídicos son estrechos y los morales amplios, ${ }^{97}$ no puede haber imputación ética demeritoria. ${ }^{98}$ Tampoco la mera omisión de un deber de moral puede ser imputada, puesto que "La omisión de una acción generosa no es ninguna culpabilidad”. ${ }^{99}$ Esta interpretación se ve sustentada por la afirmación hecha por Kant en el manuscrito de las Lecciones MPC, ${ }^{100}$

96 Timmons, Mark, "Evil and Imputation in Kant's Ethiks”, enJahrbuch für Recht und Ethik (T. 1994), II, p. 122.

${ }^{97}$ Kant, Immanuel, MdS, cit. (n. 13), p. 390.

${ }^{98}$ Para otra postura, sustentada por Blöser, negar la imposibilidad de una imputación al demérito en la imputación ética contradice la tesis de Kant que, también en la ética hay estrechos deberes perfectos contra sí mismo, que prohíben determinadas acciones, por ejemplo el suicidio, la masturbación, comer y beber en exceso o mentir. En referencia e estos deberes morales estrechos también pueden ser imputadas acciones individuales a la culpabilidad ética. BLÖSER, Claudia, cit. (n. 9), p. 33. Esta distinción entre la transgresión de deberes éticos amplios y deberes éticos estrechos se basa en que Kant primero lo llama falta de virtud (Untugend) y a los segundos vicio (Laster). Kant, Immanuel, $M d S$, cit. (n.), p. 464. Además, esta última tesis se ve sustentada por la afirmación hecha por Kant que al hablar de la transgresión de deberes morales que no conllevan demérito, se está refiriendo a los deberes imperfectos (unvollkommene Pflichten). KANT, Immanuel, MdS, cit. (n. 13), p. 390.

99 Kant, Immanuel, PPP, cit. (n. 39), p. 155.

${ }^{100}$ Georg Ludwig Collins, asistió al curso sobre filosofía moral perteneciente al semestre de invierno 1784/85. Las notas de Collins son casi indistinguibles tanto en el orden como en el contenido de las notas que publicó Paul Menzer. Este, sin embargo, no basó su texto publicado en Collins sino en un cuaderno (que parece ahora haber desaparecido) perteneciente a un estudiante de apellido Brauer. Él lo complementó con el material del cuaderno de Mrongovius y de un tercer cuaderno, perteneciente a un tal Kutzner. Lehmann lo seleccionó para la primer volumen de notas publicadas por la Academia. Al pertenecer al grupo de notas derivadas de un ancestro común, su fecha estimada de producción abarca los años 1774/75-1776/77. Kühn sugiere que Collins compró un conjunto de notas ya preparado. KüHN, Manfred, “Collins: Kant's photo-critical position", en Denis, Lara (editora) Kant's Lectures on Ethics. A Critical Guide. (Cambridge, Cambridge University Press, 2015), p. 51. La fecha de las notas al margen, se supone que datan del semestre de invierno de 1784/1785. Schwaiger, sin embargo, sostiene que las notas al margen datan de la misma fecha que su producción. SCHWAIGER, C., cit. (n. 38), pp. 183-184. La importancia del manuscrito, supuestamente producido por Collins, radicaría en que asistió a las conferencias en el mismo periodo en que Kant publica la Fundamentación de la metafísica de las costumbres (GMdS). Sin embargo esto es falso por dos motivos. En primer lugar, su origen data de los años antes señalados. En segundo lugar, porque 
así: "Como el hombre es libre en lo que atañe al ejercicio de sus acciones morales, le pueden ser imputadas, por consiguiente, todas las consecuencias que se originan en tales acciones; pero las consecuencias que se desprenden de la inhibición en acometer las acciones morales no pueden ser imputadas, ya que no puede ser considerada como una acción dejar de hacer lo que no estoy obligado a hacer (...) Por lo tanto, las omisiones éticas no constituyen acción alguna; sin embargo, las omisiones jurídicas sí son acciones y pueden ser imputadas, ya que se trata de inhibiciones de algo a lo que puedo ser obligado por la ley". ${ }^{101}$ Este pasaje evidencia que Kant, en primer lugar, opina que sólo omisiones de acciones respecto de las cuales se estaba obligado, son imputables. Así como sucede, por ejemplo, con la omisión de prestar auxilio; cuando una persona está obligada a una acción, puede imputársele la omisión. En segundo lugar, determinadas omisiones se denominan acciones, lo que indica una particularidad terminológica; las omisiones que son imputables, Kant las denomina "acciones", de modo que afirma que sólo las acciones son imputables y no es necesario mencionar a las omisiones. En tercer lugar, no acepta ningún deber en referencia a acciones éticas, sino sólo en relación a acciones jurídicas, puesto que la omisión de acciones éticas no puede ser imputada. ${ }^{102}$

En la imputación jurídica, en cambio, no existe discusión en torno a la imputación de las consecuencias. En esta clase de imputación, una vez

si bien la publicación de la GMdS data del año 1785, ello se debió a un retraso en la publicación. Kant había terminado su obra, al menos un año antes. Además, analizando el contenido del manuscrito, surge que las ideas plasmadas en aquella obra, se encuentran en el manuscrito sólo en un estado embrionario.

101 Kant, Immanuel "Moralphilosophie Collins", en AKAdEmie DER WissenSCHAFTEN DER DDR (editor), Kant's gesammelte Schriften (Berlin, Editorial Walter de Gruyter, , 1974), XXVII/1.1, p. 290.

102 Aquí, se dividen las aguas, para la opinión mayoritaria las omisiones en el ámbito de la ética no son imputables. Sin embargo, este tercer punto evidencia, según Blöser, la cuestión si, según Kant, existe en general un deber a la acción. Vastas leyes morales no prescriben, en la teoría de Kant, ninguna acción concreta, por lo que parece desprenderse, que en la ética, las omisiones no son imputables. Aunque Kant denomina en la MdS-T d omisiones éticas que son imputables y, de hecho, la omisión de un deber, que proviene del respeto debido a todo hombre como tal, es el vicio (Laster). Al respecto afirma: "La omisión de un mero deber de amor es falta de virtud (peccatum). Pero la omisión del deber que derivada, en general, del respeto debido a todo hombre como tal es un vicio (viticium). Luego, de la inobservancia del primero ningún hombre es ofendido, a través de la omisión del segundo ocurre la ruptura del legítimo reclamo del hombre”. KANT, Immanuel, $M d S$, cit. (n. 13), p. 464. Se torna evidente - diverso a como Kant menciona en las Lecciones - que no son deberes éticos como tal (deberes perfectos), cuya omisión no es imputable, sino amplios deberes de virtud (deberes imperfectos). BlösER, Claudia, cit. (n. 9), p. 23. 
imputado el hecho al artífice y medido con respecto a la norma, tiene lugar la imputatio iuris, conforme al cual ese hecho es atribuido a título de recompensa, si el sujeto realiza más de lo debido o a título culpabilidad, si el sujeto realiza menos de lo exigido por la norma. Resulta necesario aclarar que para Kant los hechos debidos no son imputados y el proceso se detiene en el primer nivel de imputación puesto que "...la adecuación de la conducta a lo que es debido no tiene efecto jurídico". ${ }^{103}$ En este caso la no atribución de efectos jurídicos a la conducta debida es una consecuencia lógica de la falta de imputación de primer nivel. Dado que el autor no actúa libremente sino en cumplimiento del deber, Kant considera a dicha acción como no libre y, por lo tanto, niega que la acción del autor sea un "factum" imputable. Esta afirmación no la realiza en la MdS, sino que aparece en otras obras, considerando que ninguna conducta que se encuentre bajo la obligación de actuar u omitir puede ser imputada siendo sólo imputable las acciones basadas en la libertad. ${ }^{104}$

Respecto de sus consecuencias de los hechos que se ubican por encima o bien, por debajo de lo debido Kant afirma que "Las consecuencias buenas o malas de una acción debida - lo mismo que las consecuencias de la omisión de una meritoria - no pueden imputarse al sujeto (modus imputationis tollens).

Las consecuencias buenas de una acción meritoria -lo mismo que las consecuencias malas de una acción injusta- pueden imputarse al sujeto (modus imputationis ponens)". ${ }^{105}$ Mediante el uso de las expresiones modus imputationis ponens y modus imputationis tollens, Kant está aludiendo a dos conceptos comúnmente usados en lógica: modus ponens y modus tollens, dichos conceptos le sirven para limitar las consecuencias a imputar. Kant a través de modus imputationis tollens quiere significar que las consecuencias de una acción debida no son reprochables, del mismo modo que dejar de realizar algo que va más allá de lo debido. El modus imputationis ponens, por su parte, permite imputar tanto las consecuencias buenas de una acción meritoria como las consecuencias malas de la acción reprochable. De la síntesis de ambas reglas podemos afirmar que una condición necesaria para la imputación de las consecuencias de una acción es que la acción sea una acción ilícita o una acción meritoria, puesto que las consecuencias de una acción debida no son imputadas. Sólo las malas (y no las buenas) conse-

${ }^{103}$ Kant, Immanuel, $M d S$, cit. (n. 13), p. 228.

${ }^{104}$ Nada que sea conforme a las leyes y, en cuya consideración estamos obligados a cometer u omitir algo puede ser imputado. Luego, sólo una acción, que se basa en la libertad, es imputable, y la libertad misma no es nada más que la capacidad de imputación (receptivitas imputationis). KANT, Immanuel, $M d S-V$, cit. (n. 33), p. 564.

105 Kant, Immanuel, $M d S$, cit. (n. 13), p. 228. 
cuencias de un acto ilícito y sólo las buenas (y no las malas) consecuencias de un acto meritorio son imputables. Imputar buenas consecuencias de una acción ilícita sería contraintuitivo. Del mismo modo sería contraintuitivo imputar las malas consecuencias de una acción meritoria. ${ }^{106} \mathrm{Si}$ analizamos el pasaje de Kant sobre las consecuencias de la imputación podemos llegar a la conclusión de que, desde el punto de vista de laatribución a la culpabilidad, las afirmaciones de Kant son las siguientes: (1) las malas consecuencias de un acto que fue debido (exactamente requerido) (debitum) no pueden ser imputadas al agente, (2) las malas consecuencias de no hacer lo que es meritorio tampoco puede ser imputadas, (3) las malas consecuencias de actos incorrectos pueden ser imputadas. ${ }^{107}$

\section{EL CONOCIMIENTO DEL HECHO SEGÚN KANT: DOLO Y CULPA EN LA TEORÍA KANTIANA}

Para que las consecuencias del hecho sean imputadas, Kant exige que el agente actué con conocimiento del hecho y de la calificación del mismo, es decir, que conozca el carácter valioso o desvalorado del mismo. No hay hecho sin consciencia del sujeto. Y la consciencia es diferente según recaiga sobre la mera realización del hecho, o bien, sobre el carácter del hecho como meritorio (o reprobado, según el caso). La imputación exige ambas formas de consciencia. Respecto de la imputación del hecho a título de recompensa, es necesario que el Urheber actúe en vistas de dicha recompensa: no basta un mero conocimiento de las circunstancias del hecho que estarían implícitas en la imputación del suceso como hecho, se requiere además que el sujeto conozca el carácter recompensado del hecho establecido por ley. ${ }^{108}$ Las mismas exigencias deben extraerse respecto de la conducta que realiza menos de lo debido. No basta para atribuir el hecho como culpable que el autor conozca las circunstancias del hecho, se requiere además que el sujeto conozca el carácter prohibido de la conducta o, en otros términos, el actor debe saber que la conducta está amenazada con pena. En síntesis, la imputación implica el conocimiento de los motivos del agente que acompañan al hecho en cuestión: tanto el carácter prohibido, si se trata de un delito, como del carácter recompensado, si se trata de algo meritorio.

Kant no sólo atribuye responsabilidad cuando el agente actúa con conocimiento del hecho, sino también cuando el mismo falta. La diferencia entre uno y otro caso reside en el grado de imputación. Dicha oposición

106 BrRd, Sharon, HruschKa, Joachim, cit. (n. 28), p. 310.

107 Hill, Thomas, "Kant on Responsibility for Consequences" Jahrbuch für Recht und Ethik, (1994), II, p. 161.

108 SÁnchez-Ostiz, Pablo, cit. (n. 80), p. 112. 
se refleja en el pasaje de la In troducción a la $\mathrm{MdS}$ cuando sostiene que "una transgresión realizada sin dolo que, no obstante, puede ser imputada, se llama simple culpa (culpa). Un realizada con dolo (esto es, aquella que está ligada a la conciencia de que es una infracción) se llama delito (dolus)" ${ }^{109}$ Esta distinción puede ser confirmada mediante sus Lecciones, donde afirma que "una acción emprendida con dolo, o sea, con consciencia de la prohibición legal según una reflexión anterior, debe ser mucho más imputada que cuando ella no ocurre deliberato animo". ${ }^{110}$ Ante casos de hechos dolosos estamos en presencia de una mayor libertad del sujeto y por ello conllevan una imputación mayor. Resulta necesario destacar que Kant utiliza el concepto de dolo no en los términos de la dogmática jurídico-penal actual, es decir, como "dolo avalorado", que sólo abarca el conocimiento y voluntad del hecho pero no el de la antijuridicidad de la conducta, sino como "dolo desvalorado", cuyo objeto es el conocimiento y voluntad de la conducta ilícita.

Respecto de las acciones impudentes Kant aclara "incluso si la acción no ocurrió ex proposito animo, puede, sin embargo, ser imputada por las consecuencias contingentes de una acción, si contiene una infracción del deber; aunque ciertamente es menos imputable, que cuando él [agente] ha debido y podido prever las consecuencias de la acción". ${ }^{111}$ Acertadamente, Kant imputa consecuencias no queridas de una acción, ubicando el núcleo de la acción imprudente en la infracción del deber. Para Kant este tipo de conductas "sólo pueden ser imputadas de manera indirecta". ${ }^{112}$ A su vez, reconoce el menor grado de reproche de este tipo de acciones. Sin embargo, Kant no desarrolla los presupuestos de una imputación indirecta o extraordinaria (außerordentliche Zurechnung), como ya la había reconocido Pufendorf, sino sólo se limita a aclarar que la diferencia entre dolo y culpa es una cuestión de grado de imputación.

\section{Consideraciones FINALES}

Cotidianamente imputamos acciones. Todas las valoraciones de nuestro accionar transitan por los polos de la alabanza y el reproche. Normalmente no diferenciamos niveles de imputación. A menudo el actor es identificado y, simultáneamente, su acción es valorada junto con su persona, por ejemplo en la afirmación “¡usted es un mentiroso!”, no sólo consideramos al autor como co-sujeto, o sea, como persona sino que, también le repro-

\footnotetext{
109 Kant, Immanuel, $M d S$, cit. (n. 13), p. 224.

110 Kant, Immanuel, $M d S-V$, cit. (n. 33), p. 568.

111 Kant, Immanuel, $M d S$ - $V$, cit. (n. 33), p. 469.

112 Kant, Immanuel, $M d S$ - $V$, cit. (n. 33), p. 468.
} 
chamos el hecho de mentir. En dicha afirmación no es posible, a priori, diferenciar los diversos juicios implicados en el proceso imputativo. La diferencia de ambos niveles de imputación es importante, en especial porque ella permite diferenciar los aspectos descriptivos (applicatio legis ad factum) de la imputación, la primera todavía no contiene ninguna valoración, sino sólo crea el presupuesto para ello; la acción es evaluada a través de la aplicación de la ley y la persona es valorada a través de la imputación al mérito o a la culpabilidad. ${ }^{113}$

Kant erigió a la teoría de la imputación en un lugar central de la MdS, constituyendo un concepto central de su filosofía práctica. El hecho que sólo la haya establecido su definición y no haya hecho un desarrollo analítico del mismo, como solía hacer en sus clases de filosofía moral, hizo que la imputación no fuese suficientemente estudiada. Hoy, a partir del análisis de obras complementarias, no publicadas por el propio Kant, es posible echar un poco de luz a los problemas que genera la teoría.

En el sistema presentado por Kant la capacidad de imputación (imputabilitas) y la imputación al hecho son condiciones necesarias para la imputación a la culpabilidad o al mérito, vale a la inversa, que la relevancia práctica de la capacidad de imputación y de la imputación al hecho consiste en que ellas establecen la valoración de la acción y de la persona. La relación de ambos niveles de imputación se pueden, consiguientemente, formular de la siguiente manera: la imputación al hecho expresa que una persona imputable ha realizado una acción (un hecho en la terminología kantiana) $y$, en cuanto a cual, ella es imputable es decir, se valora la capacidad de imputación situacional con vista a la acción concreta. ${ }^{114}$ Las acciones sólo son relevantes normativamente si se ubican por encima o por debajo de lo exigido por el deber. Las meras acciones debidas, no son imputables. La determinación de si la conducta realiza más o menos de lo que la ley exige es el ámbito de la applicatio legis ad factum. Acto seguido se procede a imputar las consecuencias (imputación al mérito o a la culpabilidad). Kant no es consciente de estos juicios diferenciados, en un mismo acto, mide e imputa las consecuencias, denominándolas “imputatio legis".

\section{BibliografíA}

ADICKES, Erich, (1911) Einleitung in die Abtheilung des handschriftlichen Nachlasses, en KANT, Immanuel, Kant's gesammelte Schriften (Berlin-Leipzig, Walter de Gruyter, 1925), XIV, pp. XV-LXII.

113 BlÖSER, Claudia, cit. (n. 9), p. 41.

114 BlÖSER, Claudia, cit.(n. 9), p. 43. 
BLÖSER, Claudia, Zurechnung bei Kant. Zum Zusammenhang von Person und Handlung in Kants praktischer Philosophie (Berlin, Walter de Gruyter, 2014)

BERNSTEIN, Richard, La reestructuración de la teoría social y política (traducción castellana de Eduardo L. Suárez, Ciudad de México, Fondo de Cultura Económica, 1982).

BYrd, Sharon; HruschKa, Joachim, Kant's Doctrine of Right (Cambridge, Cambridge University Press, 2010).

Denis, Lara (editora) Kant's Lectures on Ethics. A Critical Guide (Cambridge, Cambridge University Press, 2015).

FleTCHer, George, Gramática del Derecho penal (traducción castellana de Francisco Muñoz Conde, Buenos Aires, Hammurabi, 2008).

HiLl, Thomas, Kant on Responsibility for Consequences, en Jahrbuch für Recht und Ethik, (Berlin, Duncker \& Humblot, T. II, 1994), pp. 159-175.

Hollis, Martin, Filosofía de las Ciencias Sociales (traducción castellana de Ana Lizón, Barcelona, Ariel, 1998).

HruschKa, Joachim, On the logic of imputation in the Vigilantius lecture notes, en DeNIS, Lara (editora) Kant's Lectures on Ethics. A Critical Guide (Cambridge, Cambridge University Press, 2015), pp. -170-184.

HruschKa, Joachim, Das deontologische Sechseck in der Jurisprudenz, en Recht der Wirtschaft und der Arbeit in Europa. Gedächtnisschrift für Wolfgang Blomeyer (Berlin, Dunker \& Humblot, 2010), pp. 775-788.

HruschKa, Joachim, Die ,Verabschiedung' Kants durch Ulrich Klug im Jahre 1968: Einige Korrekturen, en Zeitschrift für die gesamte Strafrechtwissenschaft, (2010), CXXII, pp. 493-503.

Hruschka, Joachim, Die Würde des Menschen bei Kant, en Archiv für Rechts- und Sozialphilosophie (2002), LXXXIII/ III, pp. 463-480.

HruschKA, Joachim, Verhaltensregeln und Zurechnungsregeln, en Rechtstheorie. Zeitschrift für Logik, Methodenlehre, Kybernetik und Soziologie des Rechts (1991), XXII, pp. 449-460.

HruSCHKA, Joachim, Rechtfertigungs- und Entschuldigungsgründe: Das Brett des Karneades bei Gentz und bei Kant, en Goltdammer's Archiv für Strafrecht (1991), pp. 1-10.

HruschKa, Joachim, Imputation, en Birgham Young University Law Review, Issue 3, (1986), pp. 669-710.

HruschKa, Joachim, Strukturen der Zurechnung, (Berlin, Walter de Gruyter, 1976). JoERden, Jan, "Zwei Formeln in Kants Zurechnungslehre”, en Archiv für Rechts- und Sozialphilosophie (1991), pp. 525-538

Kelsen, Hans, Reine Rechtslehre (Wien, Franz Deuticke, 1960).

KüHn, Manfred, "Collins: Kant's photo-critical position" Kant's Lectures on Ethics. A Critical Guide. (Cambridge, Cambridge University Press, 2015), pp 51-67.-LEHManN, Gerhard, "Vorwort", en Kant, Immanuel, Kant's gesammelte Schriften, (Berlin, Walter de Gruyter, , 1955), XXIII, p. V.

Llanos Cifuentes, Alejandro, Fenómeno y trascendencia en Kant (Pamplona, Universidad de Navarra, 2002).-LoudEn, Robert, "Vigilantius: moraly for Humans", en Denis, Lara (editora) Kant's Lectures on Ethics. A Critical Guide (Cambridge, Cambridge University Press, 2015), pp. 84-99.

MerLe, Jean-Christophe, German Idealism and the Concept of Punishment (New York, Cambridge University Press, 2009).

PAWLIK, Michael, Das Unrecht des Bürgers. Grundlinien der Allgemeinen Verbrechenslehre (Tübingen, Mohr Siebeck, 2012). 
POTter, Nelson, "Kant on Obligation and Motivation in Law and Ethics", en Jahrbuch für Recht und Ethik, (1994), II, pp. 95-111.

Ricceur, Paul, "Le concept de responsabilité. Essai d'analyse sémantique", en EL MISMO, Le juste I (Paris, Esprit, 1995).

SÁnchez-Ostiz, Pablo, Imputación y teoría del delito. La teoría kantiana de la imputación y su recepción en el pensamiento jurídico-penal contemporáneo (Buenos Aires, B de F, 1998).

Santos Herceg, José C., "Estudio introductorio", en Kant, Immanuel, Reflexiones sobre filosofía moral (Salamanca, Ediciones Sígueme, 2004), pp. 9-32.

StockHammer, Morris, Kants Zurechnungsidee und Freiheitsantinomie (Köln, Kölner Universitäts Verlag, 1961).

SCHWAiger, Clemens "Die Vorlesungsnachschriften zu Kants praktischer Philosophie in der Akademie-Ausgabe" Kant-Studien 91 (2000), pp. 178-188.

Timmons, Mark, "Evil and Imputation in Kant's Ethiks", en Jahrbuch für Recht und Ethik (1994), II, pp. 113-141.

WINCH, Peter, (1958) The Idea of a Social Science and its Relation to Philosophy (London, Routledge, 2003).

Wittgenstein, Ludwig, (1953) Investigaciones filosóficas (traducción castellana de Alfonso García Suárez y Ulises Moulines, Barcelona, Atalaya, 1999).

WooD, Allen, Kantian Ethics (Cambridge, Cambridge University Press, 2008). 
